\title{
APLIKASI KITOSAN-FOSFAT UNTUK MENINGKATKAN SIFAT TAHAN API KAIN KAPAS
}

\author{
APPLICATION OF CHITOSAN-PHOSPHATE TO IMPROVE FLAME \\ RETARDANT OF COTTON FABRIC
}

\author{
Cica Kasipah, Rizka Yulina, Wulan Septiani, Rr. Srie Gustiani, Mochammad Danny Sukardan \\ Balai Besar Tekstil, Jalan Jenderal Ahmad Yani No. 390 Bandung \\ E-mail: texirdti@bdg.centrin.net.id
}

Tanggal diterima: 6 Mei 2019, direvisi: 28 Desember 2019, disetujui terbit: 28 Desember 2019

\begin{abstract}
ABSTRAK
Penggunaan zat tahan api pada tekstil yang bersifat ramah lingkungan sangat diperlukan untuk menggantikan zat tahan api yang bersifat toksik. Pada penelitian ini telah dilakukan aplikasi kitosan-fosfat sebagai zat tahan api yang bersifat ramah lingkungan untuk meningkatkan sifat tahan api kain kapas. Metode penelitian meliputi pelapisan kitosan dan amonium polifosfat pada kain kapas yang dilakukan dengan 2 tahapan proses. Tahap 1 pelapisan kitosan pada serat kapas dengan cara perendaman, dilanjutkan tahap 2 pelapisan amonium polifosfat pada kain kapas yang telah mengandung kitosan dengan cara pad-dry-cure. Evaluasi dan pengujian dilakukan terhadap sifat tahan api kain kapas sebelum dan sesudah diproses dengan kitosan dan amonium polifosfat dengan metode SNI 0989:2011, uji morfologi permukaan kain kapas menggunakan SEM (Scanning Electron Microscope), serta uji sifat termal kain kapas menggunakan TGA. Melalui 2 tahap proses pelapisan kitosan dan amonium polifosfat pada kain kapas, diperoleh kain kapas yang bersifat tahan api dengan kondisi optimum pelapisan kitosan $1 \%$ dan amonium polifosfat $2 \%$. Hasil uji menunjukkan bahwa waktu perambatan nyala api 0 detik, dekomposisi termal pada temperatur $298^{\circ} \mathrm{C}$ jauh lebih rendah daripada kain kapas kontrol yaitu $374^{\circ} \mathrm{C}$, dan pada temperatur $500^{\circ} \mathrm{C}$ menyisakan residu sampel sebesar 38,7\% jauh lebih besar dibandingkan residu kain kapas kontrol sebesar 8,9\%. Penurunan temperatur dekomposisi termal dan peningkatan jumlah residu pada sampel kain kitosan-fosfat menunjukkan bahwa kain kapas kitosan-fosfat hasil penelitian ini telah tebukti memiliki sifat tahan api.
\end{abstract}

Kata kunci: tahan api, kitosan, pad-dry-cure, kain kapas

\section{ABSTRACT}

The use of environmental friendly flame retardant agent in textiles is very necessary to replace the toxic flame retardant agent. In this research, the application of environmental friendly chitosan-phosphate to improve the flame retardant properties of cotton fabrics has been carried out. The research methods included the coating of chitosan and ammonium polyphosphate on cotton fabric which was carried out in 2 process steps. Step 1 was the coating chitosan on cotton fiber by immersion, followed by step 2 which was the coating of ammonium polyphosphate on cotton fabric containing chitosan using pad-dry-cure system. Evaluation and testing were carried out on flame retardant properties of cotton fabrics before and after being processed with chitosan and ammonium polyphosphate using SNI 0989: 2011 method, the morphological testing on cotton fabric surfaces using Scanning Electron Microscope (SEM), and the thermal properties of cotton fabrics using (Thermogravimetri Analysis) TGA. Through the two steps chitosan and ammonium polyphosphate coating on cotton fiber, the cotton fabric with flame retardant property was observed at optimum coating conditions of $1 \%$ chitosan and $2 \%$ ammonium polyphosphate. The testing results show that the flame propagation time was 0 seconds, the thermal decomposition at $298^{\circ} \mathrm{C}$ was lower than the control cotton fabric, which was $374^{\circ} \mathrm{C}$, and at a temperature of $500^{\circ} \mathrm{C}$, the sample residue left was $38.7 \%$, greater than the control cotton fabric residue which was $8.9 \%$. A decrease in thermal decompositon temperature and an increase in the amount of residue on the chitosan-phosphate cotton fabric sample shows that the chitosan-phosphate cotton fabric produced in this study has been proven to have a flame retardant property.

Keywords: flame retardant, chitosan, pad-dry-cure, cotton fabric

\section{PENDAHULUAN}

Serat selulosa pada kain kapas merupakan salah satu biopolimer terpenting di dunia. Keuntungan utamanya adalah ketersediaan dalam jumlah besar, memiliki sifat mekanik yang bagus, biodegradabilitas, dan hidrofilisitas yang tinggi. ${ }^{1}$

Kain kapas banyak digunakan baik sebagai kain sandang maupun sebagai kain non-sandang. 
Kain kapas sebagai kain sandang, banyak digunakan sebagai kain untuk pakaian seragam, diantaranya sebagai seragam pekerja/karyawan dan juga seragam militer. Sedangkan sebagai kain nonsandang, kain kapas banyak digunakan sebagai kain untuk tekstil interior maupun tekstil pada transportasi. ${ }^{2,3}$

Sifat tahan api sering diperlukan pada kain kapas dalam berbagai penggunaannya, yaitu sebagai kain sandang bila digunakan untuk pakaian pekerja industri pertambangan, industri kimia bahkan pemadam kebakaran, serta sebagai kain non-sandang untuk tekstil interior dan tekstil pada alat transportasi sebagai kain jok. ${ }^{3,4}$ untuk meningkatkan sifat tahan api pada produk tekstil digunakan senyawa yang bersifat tahan api, yang populer adalah yang berbasis halogen, akan tetapi senyawa tersebut bersifat korosif, dapat menimbulkan senyawa dioksin, karsinogen dan diduga memberikan produk samping berupa uap beracun $\mathrm{HBr}$ dan $\mathrm{HCl}^{5}$

Dekomposisi termal selulosa terjadi diatas temperatur $300^{\circ} \mathrm{C}$ melalui dua cara. Cara pertama, proses dehidrasi disertai dekomposisi rantai glikosil membentuk arang dan air (persamaan 1) yang dominan terjadi pada suhu rendah. Cara kedua, pemutusan rantai glikosil dengan transglikosilasi intermolekuler untuk membentuk levoglukan yang dominan terjadi pada suhu tinggi, kemudian levoglukan terdekomposisi termal dan melepaskan sejumlah besar gas mudah terbakar, cairan, tar, dan arang. Gas-gas ini menyebabkan pembakaran dan menghasilkan tambahan panas untuk mengubah cairan dan tar menjadi uap yang mudah terbakar dan menyebarkan rambatan api hingga tersisa residu karbon (persamaan 2). ${ }^{6}$

Selulosa $\longrightarrow 6 \mathrm{nC}($ karbon $)+5 \mathrm{nH}_{2} \mathrm{O}$ (air) ...... (1)

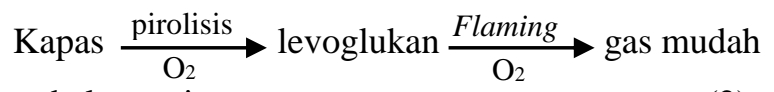
terbakar, cairan, tar, arang

Zat tahan api yang saat ini digunakan sebagai pengganti senyawa berbasis halogen yakni zat tahan api berbasis fosfor karena mempunyai sifat toksisitas yang rendah, produk sampingnya ramah lingkungan, dan uap yang ditimbulkan lebih sedikit. Akan tetapi kelemahanya, kain terbakar setelah terkena api, walaupun terbentuk arang pada sisa pembakarannya. ${ }^{5}$ Kitosan mempunyai gugus hidroksil dan gugus amino bila digunakan bersamasama dengan amonium polifosfat diharapkan dapat meningkatkan sifat tahan api amonium polifosfat pada kain kapas dengan adanya ikatan ionik dengan fosfor. ${ }^{7}$ Ikatan kitosan dengan fosfor menurut
Matevosyan, G.L. dkk dinyatakan menurut reaksi pada Gambar 1.

Kitosan adalah biopolimer alam berupa polisakarida linier dari $\beta$-1,4-D-glukosamina. Dengan adanya kandungan gugus amina primer yang bersifat kationik, pada $\mathrm{pH}<6,5$ kitosan yang berada dalam larutan akan bermuatan positif sehingga kitosan merupakan polimer polikationik. ${ }^{8}$

Pelapisan kitosan pada kain kapas telah dilakukan oleh Winiati. W, $\mathrm{dkk}^{9,10}$ yaitu pelapisan kitosan pada kain kapas dengan cara perendaman/exhaust menurut reaksi yang ditunjukkan pada Gambar 2. Dari percobaan tersebut diperoleh bahwa proses pelapisan kitosan pada kain kapas dengan cara exhaust telah berhasil dilakukan. Oksidasi selulosa baik dengan senyawa $\mathrm{KIO}_{4}$ (kalium metaperiodat) ataupun $\mathrm{NaIO}_{4}$ (natrium metaperiodat) menyebabkan terjadinya oksidasi pada gugus hidroksil C2 dan C3 yang menghasilkan gugus 2,3-dialdehida. Gugus-gugus dialdehida tersebut dapat berikatan dengan gugus amino pada kitosan membentuk ikatan yang dapat melapiskan kitosan pada permukaan kapas.

Pada penelitian ini dilakukan ko-aplikasi kitosan dan amonium polifosfat untuk meningkatkan sifat tahan api kain kapas dengan 2 tahapan proses, yaitu tahap 1 pelapisan kitosan pada serat kapas dengan cara perendaman dengan variasi konsentrasi kitosan $0,5 \%$ dan $1 \%$, dilanjutkan tahap 2 pelapisan amonium polifosfat pada kain kapas yg telah mengandung kitosan dengan cara pad-drycure dengan variasi konsentrasi amonium polifosfat 1-5\%. Dengan cara ini, diharapkan akan diperoleh kain kapas tahan api yang lebih baik serta proses dan produk yang ramah lingkungan. Keberhasilan pelapisan kitosan dan amonium polifosfat pada kain diamati dengan melakukan pengujian tahan api, uji morfologi menggunakan SEM (scanning electron microscope), dan uji TGA (thermogravimetry analysis).

\section{METODE Bahan}

Kain kapas dengan berat $0,361 \mathrm{~kg} / \mathrm{m}^{2}$, amonium polifosfat grade teknis, kitosan grade industri diperoleh dari PT. Biotech Surindo Cirebon, asam asetat grade p.a, natrium metaperiodat grade p.a. diperoleh dari Merck.

\section{Peralatan}

Peralatan yang digunakan meliputi mesin pad-dry-cure skala laboratorium, overhead stirrer, dan microwave oven. 


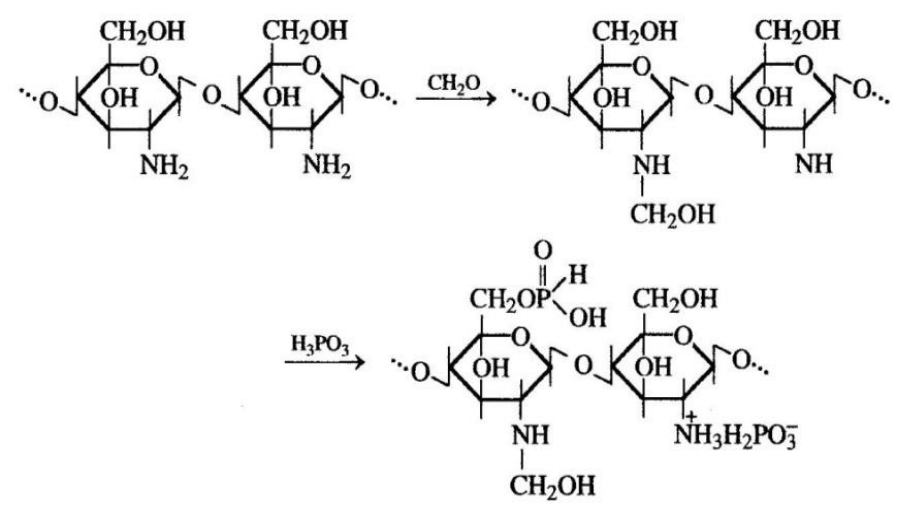

Gambar 1. Reaksi kitosan dengan fosfor dengan adanya formaldehida ${ }^{7}$
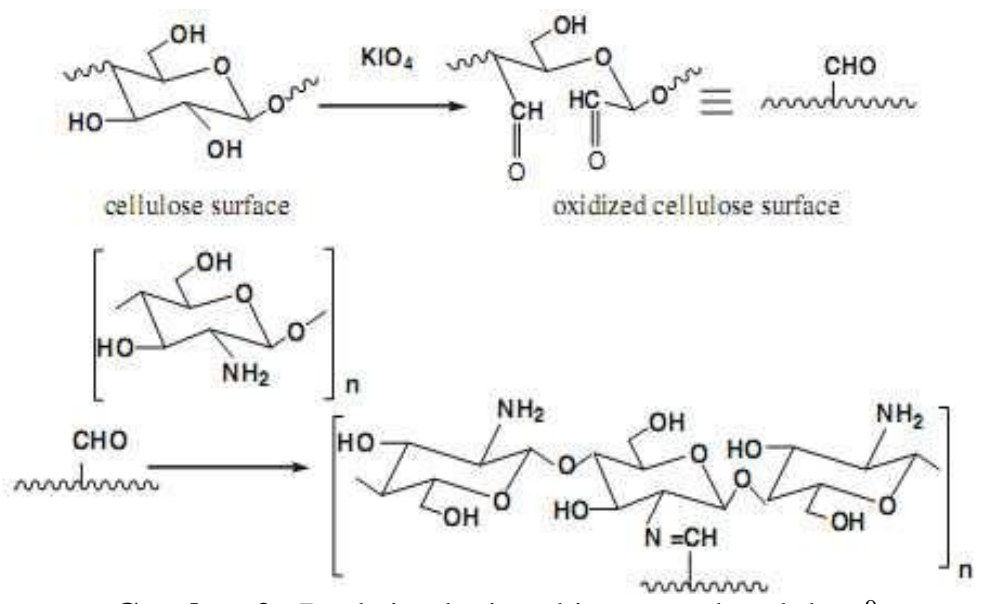

Gambar 2. Reaksi pelapisan kitosan pada selulosa ${ }^{9}$

\section{Prosedur Kerja}

- Potong kain ukuran 30 x $35 \mathrm{~cm}$

- Buat larutan kitosan dengan variasi konsentrasi $0,5 \%$ dan $1 \%(\mathrm{~b} / \mathrm{v})$ dalam asam asetat $1 \%(\mathrm{v} / \mathrm{v})$

- Buat larutan amonium polifosfat dengan variasi konsentrasi $1 \%-5 \%(b / v)$ dalam aquades

- Pelapisan kitosan dan amonium polifosfat pada kain kapas dilakukan dengan 2 tahapan proses. Tahap 1 pelapisan kitosan pada serat kapas dengan cara perendaman, dilanjutkan tahap 2 pelapisan amonium polifosfat pada kain kapas yang telah mengandung kitosan dengan cara pad-dry-cure.

- Tahap Pelapisan kitosan pada kain kapas:

- Aplikasi kitosan pada kain kapas dilakukan dengan cara perendaman, dengan penambahan natrium metaperiodat pada konsentrasi 2,5\% terhadap berat kain, dan larutan kitosan dengan variasi konsentrasi $0,5 \%$ dan $1 \%(\mathrm{~b} / \mathrm{v})$ dalam asam asetat $1 \%$, pada suhu $80^{\circ} \mathrm{C}$, vlot $1: 40$, waktu 80 menit.

- Tahap pelapisan amonium polifosfat pada kain kapas yang telah mengandung kitosan, dilakukan dengan menggunakan amonium polifosfat dengan variasi konsentrasi $1 \%-5 \%$ dalam aquades. Pada mesin padding, impregnasi kain yang telah melalui tahap pelapisan kitosan dengan larutan ammonium polifosfat, lalu peras diantara 2 rol pemeras untuk mendapatkan WPU 70\%, kemudian drying pada $100^{\circ} \mathrm{C}$ selama 3 menit dan lanjutkan dengan pelapisan pada $160^{\circ} \mathrm{C}$ selama 3 menit.

\section{Pengujian}

Pengujian sifat tahan api kain sebelum dan sesudah diproses dengan kitosan dan amonium polifosfat dengan metode SNI 0989:2011 menggunakan alat uji sifat nyala api sesuai ASTM D 1230, uji morfologi menggunakan SEM (Scanning Electron Microscope merek JEOL JSM6510/LV/A/LA), dan uji sifat termal kain kapas menggunakan TGA (Thermogravimetri Analysis).

\section{HASIL DAN PEMBAHASAN \\ Hasil uji tahan api}

Pengujian sifat tahan api kain dilakukan untuk mengetahui efektifitas penggunaan kitosanfosfat pada kain kapas untuk meningkatkan sifat tahan api kain kapas. Data hasil uji ketahanan api kain kapas hasil penelitian ditunjukkan pada tabel 1. Berdasarkan SNI 0989:2011 ${ }^{11}$, jika nyala api merambat pada kain sejauh $127 \mathrm{~mm}$ dengan waktu kurang dari 3,5 detik, dengan bahan dasar kain 
terbakar, menjadi arang atau meleleh diklasifikasikan sebagai kain yang tidak cocok pada penggunaan kain untuk pakaian. Dari data yang tertera pada Tabel 1 memperlihatkan bahwa kain kapas kontrol tanpa dilapisi dengan kitosan dan amonium polifosfat terbakar sempurna tanpa terbentuknya arang (char forming), dengan waktu terbakar 19,73 detik. Hal ini menunjukkan kain kapas kontrol tersebut dapat diterima sebagai kain untuk pakaian, akan tetapi belum memenuhi kriteria kain kapas tahan api yang dapat menghambat perambatan nyala api. Pada penelitian ini dilakukan variasi konsentrasi kitosan, yaitu $0,5 \%$ dan $1 \%$ pada kain kapas untuk mengetahui konsentrasi minimum amonium polifosfat yang masih memberikan sifat tahan api pada kain kapas. Aplikasi amonium polifosfat dilakukan pada variasi konsentrasi $1 \%$ $5 \%$.

Pada Tabel 1 ditunjukkan kain kapas yang telah dilapisi amonium polifosfat dengan variasi konsentrasi $1 \%, 2 \%, 3 \%, 4 \%, 5 \%$ tanpa terlebih dahulu dilapisi dengan kitosan menghasilkan kain yang terbakar dengan waktu perambatan nyala api rata-rata 17,8 detik, namun terjadi pengarangan. Hal ini menunjukkan bahwa amonium polifosfat dapat menghambat pembakaran pada kain kapas, sesuai dengan persamaan reaksi 3 dan 4 yang akan dijelaskan selanjutnya. Pengujian tahan api dilakukan juga pada kain kapas yang telah dilapisi dengan kitosan pada konsentrasi $0,5 \%$ dan $1 \%$ tanpa dilapisi dengan amonium polifosfat. Kain tersebut terbakar sempurna dengan waktu perambatan nyala api 18,3 detik, tanpa terjadi pengarangan. Hal ini terjadi karena kitosan merupakan senyawa organik yang mudah terbakar.
Tabel 1 juga menunjukkan bahwa kain yang telah dilapisi dengan kitosan pada konsentrasi 0,5\% dan berikatan dengan amonium polifosfat pada konsentrasi 3\%, menghasilkan kain yang tidak terbakar, dengan waktu perambatan nyala api 0 detik. Sedangkan pada konsentrasi amonium polifosfat $1 \%$ dan $2 \%$ kain kapas masih terbakar dengan waktu perambatan nyala api lebih dari 3 detik, yaitu 18,1 detik dan 19,9 detik, serta terjadi pengarangan (char forming) pada kain tersebut. Kain yang telah dilapisi dengan kitosan pada konsentrasi $1 \%$ dan amonium polifosfat pada konsentrasi $4 \%$ dan 5\% tetap tidak terbakar.

Selain itu, kain yang telah dilapisi dengan kitosan pada konsentrasi lebih tinggi, yakni $1 \%$ dan berikatan dengan amonium polifosfat pada konsentrasi $2 \%$ mampu menghasilkan kain yang tidak terbakar, dengan waktu perambatan nyala api 0 detik. Pada konsentrasi amonium polifosfat $1 \%$ kain kapas masih terbakar dengan waktu perambatan nyala api 15,6 detik, dan terjadi pengarangan (char forming) pada kain tersebut. Kain yang telah dilapisi dengan kitosan pada konsentrasi $1 \%$ dan amonium polifosfat pada konsentrasi lebih tinggi, yakni 3\%, 4\% dan 5\% tetap tidak terbakar.

Berdasarkan hasil uji pada Tabel 1, diperoleh 2 sampel kain kapas tahan api yang optimum yaitu kain kapas dengan pelapisan kitosan 0,5\%amonium polifosfat $3 \%$ dan kain kapas dengan pelapisan kitosan $1 \%$-amonium polifosfat $2 \%$. Selanjutnya, pada kedua sampel tersebut dilakukan uji morfologi menggunakan SEM dan juga sifat termal kain menggunakan TGA.

Tabel 1. Lapisi kain kapas dengan variasi konsentrasi kitosan dan amonium polifosfat (APP)

\begin{tabular}{c|c|c|c|c}
\hline Kode & $\begin{array}{c}\text { Konsentrasi } \\
\text { Kitosan }(\boldsymbol{\%})\end{array}$ & $\begin{array}{c}\text { Konsentrasi } \\
\text { APP }(\boldsymbol{\%})\end{array}$ & Waktu terbakar (detik) & $\begin{array}{c}\text { Pengarangan } \\
\text { (char forming) } \\
(-)(+)\end{array}$ \\
\hline K0APP0 & 0 & 0 & 19,73 & - \\
K0APP1 & 0 & 1 & 17,8 & + \\
K0APP2 & 0 & 2 & 17,8 & + \\
K0APP3 & 0 & 3 & 17,8 & + \\
K0APP4 & 0 & 4 & 17,8 & + \\
K0APP5 & 0 & 5 & 17,8 & + \\
K0,5APP0 & 0,5 & 0 & 18,3 & + \\
K0,5 APP1 & 0,5 & 1 & 18,1 & + \\
K0,5 APP2 & 0,5 & 2 & 19,9 & tidak terbakar \\
K0,5 APP3 & 0,5 & 3 & 0 & tidak terbakar \\
K0,5 APP4 & 0,5 & 4 & 0 & tidak terbakar \\
K0,5 APP5 & 0,5 & 5 & 0 & + \\
K1APP0 & 1 & 0 & 18,3 & tidak terbakar \\
K1APP1 & 1 & 1 & 15,6 & tidak terbakar \\
K1 APP2 & 1 & 2 & 0 & tidak terbakar \\
K1 APP3 & 1 & 3 & 0 & tidak terbakar \\
K1 APP4 & 1 & 4 & 0 & \\
K1 APP5 & 1 & 5 & 0 & \\
\hline
\end{tabular}




\section{Hasil uji morfologi dengan SEM}

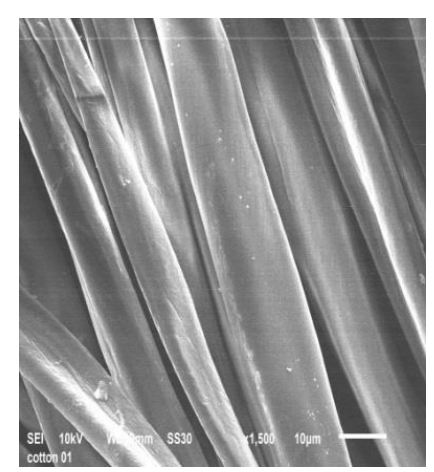

A. Kain kapas (CO)

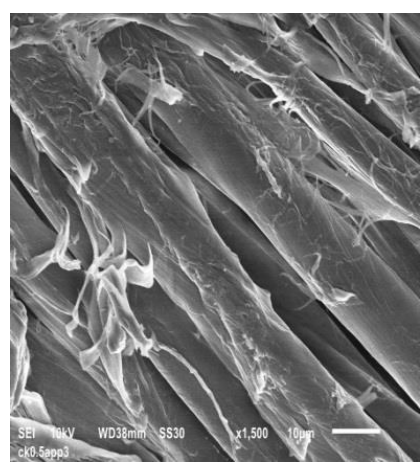

B. CK0,5APP3

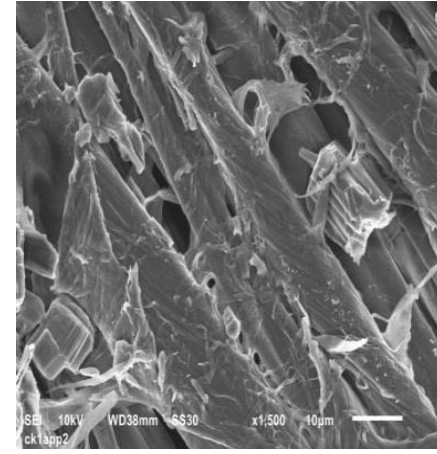

C. CK1APP2

Gambar 4 .Hasil uji SEM kain kapas yang telah dilapisi dengan kitosan dan APP

Analisis morfologi dengan SEM dilakukan untuk melihat apakah ada perbedaan antara struktur permukaan kain kapas yang telah dilapisi kitosan dan dilapisi dengan amonium polifosfat terhadap struktur permukaan kain kapas kontrol. Hasil citra SEM pada Gambar 4 menunjukkan morfologi yang menggambarkan penampang serat kapas yang dilapisi oleh kitosan-amonium polifosfat maupun tidak dilapisi. Pada Gambar 4A, dapat terlihat penampang serat kapas yang tidak dilapisi oleh kitosan-amonium polifosfat terlihat mulus dan bersih. Sedangkan pada Gambar 4B dan 4C terlihat perbedaan yang jelas penampang serat yang telah terlapisi oleh partikel kitosan-amonium polifosfat jika dibandingkan dengan Gambar 4A.

\section{Hasil uji sifat termal kain dengan TGA}

Analisis sifat termal kain dengan TGA dilakukan untuk mengetahui terjadinya dekomposisi material akibat panas pada rentang temperatur tertentu. Pada penelitian ini dilakukan analisis TGA dengan kecepatan pemanasan $30^{\circ} \mathrm{C} /$ menit pada rentang temperatur $30^{\circ} \mathrm{C}-600^{\circ} \mathrm{C}$.

Hasil uji TGA ditampilkan pada Tabel 2. Berdasarkan Tabel 2, diketahui bahwa kain kapas kontrol tanpa dilapisi kitosan dan amonium polifosfat mengalami dekomposisi termal pada temperatur $374^{\circ} \mathrm{C}$ dan pada temperatur $500^{\circ} \mathrm{C}$ menyisakan residu sampel sebesar $8,9 \%$. Sampel kain kapas yang telah dilapisi kitosan $0,5 \%$ dan $1 \%$ tanpa dilapisi amonium polifosfat mengalami dekomposisi termal pada temperatur $376^{\circ} \mathrm{C}$, dan pada temperatur $500^{\circ} \mathrm{C}$ menyisakan residu sampel sebesar 9,4\%. Hasil uji TGA kain kapas kontrol dan kain kapas berlapis kitosan tidak berbeda signifikan karena memiliki karakteristik termal dan struktur kimia yang hampir sama dan bersifat mudah terbakar.
Tabel 2. Pengaruh komposisi kitosan dan amonium polifosfat pada peningkatan sifat tahan api kain kapas

\begin{tabular}{cccc}
\hline $\begin{array}{c}\text { Konsentrasi } \\
\text { Kitosan } \\
(\%)\end{array}$ & $\begin{array}{c}\text { Konsentrasi } \\
\text { APP } \\
(\%)\end{array}$ & $\begin{array}{c}\text { Temperatur } \\
\text { dekomposisi } \\
\text { termal } \\
\left({ }^{\circ} \mathrm{C}\right)\end{array}$ & $\begin{array}{c}\% \text { Residu } \\
\text { pada 500 }\end{array}$ \\
\hline 0 & 0 & 374 & 8,9 \\
0,5 & 0 & 376 & 9,4 \\
1 & 0 & 376 & 9,4 \\
0 & 2 & 322 & 28,0 \\
0 & 3 & 313 & 26,3 \\
0,5 & 3 & 301 & 36,9 \\
1 & 2 & 298 & 38,7 \\
\hline
\end{tabular}

Sampel kain kapas yang telah dilapisi amonium polifosfat pada konsentrasi 2\% dan 3\% tanpa dilapisi kitosan mengalami dekomposisi termal pada temperatur yang jauh lebih rendah, yakni berturut-turut $322^{\circ} \mathrm{C}$ dan $313^{\circ} \mathrm{C}$. Selain itu, pada temperatur $500^{\circ} \mathrm{C}$ menyisakan residu sampel yang lebih besar yakni berturut-turut sebesar $28,0 \%$ dan $26,3 \%$. Hasil uji TGA kedua sampel tersebut tidak berbeda signifikan, sesuai dengan hasil uji tahan api pada Tabel 1, tetapi berbeda dengan kain kapas kontrol dan kain kapas berlapis kitosan. Hal ini karena senyawa fosfor pada kain kapas menghasilkan sifat tahan api dengan cara menurunkan temperatur dekomposisi melalui reaksi dehidrasi. Berdasarkan penelitian yang dilakukan oleh Tahlawy, K., ${ }^{6}$ senyawa turunan fosfor pada kain kapas dapat menahan nyala api dengan cara menurunkan temperatur dekomposisi melalui reaksi dehidrasi, dimana amonium fosfat pada saat pemanasan terdekomposisi menjadi amonia dan asam fosfat, yang kemudian mengkatalisis reaksi dehidrasi selulosa. Selain itu, senyawa turunan fosfat dapat menghambat reaksi pembakaran dengan cara mencegah pembentukan levoglukan melalui persamaan reaksi 3 dan 4 berikut ini: 
$\mathrm{R}-\mathrm{X}-\mathrm{P}(\mathrm{O})(\mathrm{OH})\left(\mathrm{ONH}_{4}\right) \rightarrow \mathrm{H}_{2} \mathrm{O}+\mathrm{H}_{3} \mathrm{PO}_{4}+\mathrm{C}_{\text {(arang) }} \ldots \ldots .$. (3)
$\mathrm{R}-\mathrm{X}-\mathrm{P}(\mathrm{O})(\mathrm{OH})(\mathrm{ONa}) \rightarrow \mathrm{H}_{2} \mathrm{O}+\mathrm{H}_{3} \mathrm{PO}_{4}+\mathrm{C}_{\text {(arang) }} \ldots \ldots \ldots$ (4)

Sifat termal kain kapas tahan api semakin terlihat jelas dengan adanya pelapisan kitosan dan amonium polifosfat pada kain kapas. Sampel kain kapas yang telah dilapisi kitosan 0,5\%-amonium polifosfat 3\% dan kain kapas dengan pelapisan kitosan $1 \%$-amonium polifosfat $2 \%$ mengalami dekomposisi termal pada temperatur yang jauh lebih rendah lagi daripada temperatur dekomposisi termal kain kapas kontrol, yaitu berturut-turut $301^{\circ} \mathrm{C}$ dan $298^{\circ} \mathrm{C}$, dan pada temperatur $500^{\circ} \mathrm{C}$ menyisakan residu sampel yang lebih besar, yakni sebesar $36,9 \%$ dan 38,7\%. Hal ini menunjukkan bahwa kitosan terbukti memberikan kontribusi cukup besar untuk menghambat nyala api pada kain kapas sebagai sumber nitogen yang dapat bereaksi dengan fosfat membentuk senyawa kitosan-fosfat yang resisten terhadap nyala api.

Berdasarkan penelitian yang dilakukan oleh Matevosyan, G.L. $\mathrm{dkk}^{7}{ }^{7}$ penggabungan kitosan dengan senyawa fosfat dapat meminimalkan degradasi asam selulosa dengan melepaskan asam fosfat melalui pembentukan kitosan-fosfat dan meningkatkan ketahanan terhadap api. Selain itu, kitosan merupakan senyawa yang mengandung unsur nitrogen dan dapat bersinergi dengan fosfor sebagaimana persamaan reaksi 5 berikut:

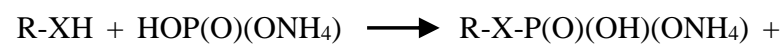

Keterangan : R-XH = kitosan

Modifikasi kimia dimana terjadi ikatan kimia antara zat penghambat api dan selulosa biasanya terjadi pada daerah amorf selulosa. ${ }^{12}$ Sebagaimana telah dijelaskan bahwa pada saat terjadi pirolisis, zat aktif yang berfungsi sebagai penghambat api (flame retardant) mengkatalisis reaksi dehidrasi, dekarboksilasi, dan pembentukan arang karena adanya elemen fosfor dan nitrogen, serta dapat menghambat produksi levoglukan. Semakin sedikit levoglukan yang terbentuk, maka akan semakin sedikit pula fragmen produk yang mudah terbakar hasil dekomposisi levoglukan sebagaimana ditunjukkan pada persamaan reaksi 2.6 Serat selulosa yang dimodifikasi dengan zat penghambat api memiliki temperatur dekomposisi yang lebih rendah, namun dengan persen residu padatan yang jauh lebih besar dibandingkan serat tanpa zat penghambat api. ${ }^{12}$ Ini sesuai dengan persen residu yang telah diperoleh pada penelitian ini sebagaimana tercantum pada Tabel 2, dimana persen residu sampel kain yang dimodifikasi dengan kitosan dan amonium polifosfat jauh lebih besar jika dibandingkan dengan kain kapas dengan ammonium polifosfat saja dan juga kain kapas tanpa perlakuan. Hal ini disebabkan pula karena hasil dari pirolisis serat yang telah dimodifikasi kimia menghasilkan produk-produk yang jauh lebih tidak mudah terbakar seperti air, karbon dioksida, dan arang (charr) serta menghambat pembentukan gas-gas yang mudah terbakar yang disebabkan oleh dekomposisi levoglukan. ${ }^{12}$

\section{KESIMPULAN}

Melalui 2 tahap proses pelapisan kitosan dan amonium polifosfat pada kain kapas, yaitu proses untuk pelapisan kitosan dengan cara perendaman dilanjutkan dengan proses pelapisan amonium polifosfat dengan cara pad-dry-cure, diperoleh kain kapas dengan kondisi optimum pelapisan kitosan $1 \%$ dan amonium polifosfat $2 \%$ yang bersifat tahan api dengan waktu perambatan nyala api 0 detik. Kain kapas yang dimodifikasi dengan kitosan $1 \%$ dan amonium polifosfat $2 \%$ memiliki temperatur dekomposisi termal yakni $298^{\circ} \mathrm{C}$, jauh lebih rendah daripada kain kapas kontrol yaitu $374^{\circ} \mathrm{C}$ Hal ini menunjukkan bahwa kain tersebut memiliki sifat tahan api. Selain itu, pada temperatur $500^{\circ} \mathrm{C}$, sampel kain kapas tahan api tersebut menyisakan residu sebesar 38,7\% jauh lebih besar dibandingkan residu kain kapas kontrol sebesar 8,9\%. Meningkatnya residu sampel kain tersebut membuktikan pula sifat tahan api kain dimana proses pembakaran kain menghasilkan lebih banyak produk yang tidak mudah terbakar.

\section{PUSTAKA}

1. Yang, Z., Wang, X., Lei., D., Fei, B., Xin, J. A Durable Flame Retardant for Cellulosic Fabrics. Polymer Degradation and Stability 97, 2467-2472 (2012).

2. Winiati, W., Septiani, W., Kasipah, C.,Wibisana, A. Aplikasi Kitosan sebagai Zat Antibakteri pada Kain Poliester-Selulosa degan cara Modifikasi Gugus poliester-selulosa. Arena Tekstil 32 (2), 93-102 (2017).

3. Nazar, S. Environmentally friendly flameretardant textiles, Environmentally friendly flame-retardant textiles, 339-368 University of Bolton, UK.

4. Das, S. Performance of Home Textiles. Woodhead Publishing India in Textiles (2010).

5. Charuchinda, S., Srikulkit, K., Mowattana, T. Co-Application of Sodium polyphosphate and Chitosan to Improve Flame Retardancy of Cotton Fabric. J. Sci. Res. Chula. Univ 30 (1) 97-107 (2005).

6. Tahlawy, K. Chitosan Phosphate: A New Way for Production of Eco-friendly Flame Retardant Cotton Textiles. Tailor and Francis 99 (3), 185-191 (2008). 
7. Carosio, F., Alongi. J., Malucelli, G. Layer by Layer Ammonium Polyphosphate-Based Coating for Flame Retardancy of PolyesterCotton Blend. Carbohydrate Polymer 88, 1460-1469 (2012).

8. Winiati, W., Kasipah, C., Septiani, W., Novarini, E., Yulina, R. Aplikasi Kitosan sebagai Anti Bakteri pada Kain PoliesterSelulosa dengan cara Perendaman. Arena Tekstil 31 (1), 1-10 (2016).

9. Winiati, W., Kasipah, C., Yulina, R., Wahyudi, T., Mulyawan, A. S., Septiani, W. Fiksasi Kitosan pada Kain Katun sebagai Anti Bakteri. Arena Tekstil 29 (1), 25-36 (2014).
10. Winiati, W., Kasipah, C., Yulina, R., Wahyudi, T., Mulyawan, A. S., Septiani, W. Pengaruh Berat Molekul Kitosan Terhadap Fiksasi Kitosan pada Kain Katun sebagai Anti Bakteri. Arena Tekstil 29 (2), 81-90 (2014).

11. SNI 0989:2011, Tekstil Sandang-Cara Uji Sifat Nyala Api.

12. Zhu, P., Sui, S., Wang, B., Sun, K., dan Sun, G. A Study of Pyrolysis and Pyrolysis Products of flame-retardant cotton fabrics by DSC, TGA, and PY-GC-MS. J. Anal. Appl. Pyrolysis 71, 645-655 (2004). 
Arena Tekstil Vol. 34 No. 2, 2019 : 49-56 